\title{
INSTRUCTION LEVEL AND SKIN COLOR EXPRESSED IN MAMMOGRAMS IN THE STATE OF GOIÁS IN 2013
}

Laine R. Martins', Guilherme A. Sampaio', Júlia J. Caetano1, Natália S. D. Mendonça1', Murilo H. C. Silva', Wêdylla V. Braga ${ }^{1}$ Faculdade de Medicina, Universidade Federal de Goiás - Goiânia (GO), Brazil.

Objectives: The objective of the present study is to compare the level of training in self-reported white, black or brown women in the mammograms performed in Goiás during the year 2013. Methodology: This is an exploratory, quantitative study which database is the Breast Cancer Information System (SISMAMA) in 2013, in Goiás, Brazil. Only women, of any age, were grouped into three groups: white, black, and brown, as they declared themselves. 257 were self-declared yellow and there was no indigenous record that year. Afterwards, they were subdivided according to the level of education. Results: Of the 51,797 women who underwent mammography in 2013 in Goiás, 8.7\% declared themselves white, 1.1\% black and $30 \%$ brown. As for white women $(4,537)$, except those who did not report their level of education, $52 \%$ had finished high school. As for black women (571), $61 \%$ of those who performed uni or bilateral screening mammograms and reported their graduation had not finished elementary school, and of the total number of women, $67 \%$ had incomplete elementary school, following this same selection criterion. Conclusion: Screening by mammography is the main means of early detection for the diagnosis of malignant neoplasms of the breast, one of the main causes of death in Brazil. It is known that the level of education of the population interferes in a significant way in the search for medical care and health care. Added to this, skin color is also related to schooling, social participation, and, consequently, individual access to health services. The data obtained in SISMAMA confirm this situation in the state of Goiás, with figures showing a higher level of training of white women who underwent mammography (full secondary education) in comparison with self-reported black or brown women, whose most prevalent level of schooling was elementary school incomplete. 